\title{
Clinical Presentations and Outcomes of Retinoblastoma Patients in relation to the Advent of New Multimodal Treatments: A 12-Year Report from Single Tertiary Referral Institute in Thailand
}

\author{
Duangnate Rojanaporn ${ }^{D}$, ${ }^{1}$ Taweevat Attaseth, ${ }^{1}$ Wimwipa Dieosuthichat, \\ Kitikul Leelawongs, ${ }^{1}$ Samart Pakakasama, ${ }^{2}$ Usanarat Anurathapan $\mathbb{D}^{2},{ }^{2}$ \\ Ekachat Chanthanaphak, ${ }^{3}$ Sirintara Singhara Na Ayudhaya, ${ }^{3}$ Rangsima Aroonroch, ${ }^{4}$ \\ and Suradej Hongeng ${ }^{2}{ }^{2}$ \\ ${ }^{1}$ Department of Ophthalmology, Faculty of Medicine Ramathibodi Hospital, Mahidol University, Bangkok 10400, Thailand \\ ${ }^{2}$ Department of Pediatrics, Faculty of Medicine Ramathibodi Hospital, Mahidol University, Bangkok 10400, Thailand \\ ${ }^{3}$ Department of Radiology, Faculty of Medicine Ramathibodi Hospital, Mahidol University, Bangkok 10400, Thailand \\ ${ }^{4}$ Department of Pathology, Faculty of Medicine Ramathibodi Hospital, Mahidol University, Bangkok 10400, Thailand
}

Correspondence should be addressed to Suradej Hongeng; suradej.hon@mahidol.ac.th

Received 21 May 2020; Revised 16 August 2020; Accepted 28 August 2020; Published 10 September 2020

Academic Editor: Biju B. Thomas

Copyright $@ 2020$ Duangnate Rojanaporn et al. This is an open access article distributed under the Creative Commons Attribution License, which permits unrestricted use, distribution, and reproduction in any medium, provided the original work is properly cited.

\begin{abstract}
Purpose. To investigate the clinical presentations and outcomes of retinoblastoma in relation to the advent of new multimodal treatments in Thailand. Patients and Methods. Retrospective case series. We evaluated the clinical presentation, staging, details of treatment, and treatment outcomes of retinoblastoma patients who were treated at Ramathibodi Hospital, Bangkok, Thailand, between January 1, 2007, and December 31, 2018. The log-rank test was used to explore clinical characteristics and treatment modalities that affected globe salvage and survival curves. Results. This study included 124 eyes of 81 patients with retinoblastoma. Forty-three patients (53.1\%) had bilateral retinoblastoma. The median age at diagnosis was 8 months (range, 1-48 months). Of 124 eyes, 9 eyes $(7.3 \%)$ had extraocular retinoblastoma and 115 eyes $(92.7 \%)$ had intraocular retinoblastoma, which were classified by the International Classification of Retinoblastoma (ICRB) as group A, 4 eyes (3.5\%); group B, 19 eyes (16.5\%); group C, 6 eyes (5.2\%); group D, 31 eyes (27\%); and group E, 56 eyes (47.8\%). Treatment included systemic chemotherapy, intra-arterial chemotherapy, ruthenium-106 plaque brachytherapy, external beam radiation therapy, cryotherapy, transpupillary thermotherapy, subtenon chemotherapy, and intravitreal chemotherapy. At the median follow-up period of 38.4 months (range, 0.2-148.2 months), the overall globe salvage rate of intraocular retinoblastoma was $51.7 \%$. For unilateral retinoblastoma, globe salvage rate was $37.5 \%$ (group B, 100\%; group C, $100 \%$; group D, $50 \%$; and group E, $18.8 \%$ ). For bilateral intraocular retinoblastoma, the globe salvage rate was $57.8 \%$ (group A, $100 \%$; group B, $94.4 \%$; group C, $100 \%$; group D, $64.7 \%$; and group E, 28.2\%). The overall survival rate was $93.8 \%$. Conclusions. Recent advanced treatment modalities have improved the probability of globe salvage. However, enucleation remains an important life-saving intervention in many advanced cases.
\end{abstract}

\section{Introduction}

Retinoblastoma is the most common primary intraocular malignant tumor in children [1], with a global incidence of approximately $7,202-8,102$ annually [2]. Of these patients, approximately $40 \%$ are in Asia-Pacific countries [3]. In Thailand, the nation-wide multicenter population-based prospective study of the incidence and survival rate of childhood cancer from Thai Pediatric Oncology Group (ThaiPOG) reported 97 cases of retinoblastoma diagnosed 
during the year 2003-2005, placing retinoblastoma as the $7^{\text {th }}$ most common childhood cancer in Thailand, with the incidence of 3.1 per million population [4]. The predicted incidence of retinoblastoma in Thailand, calculated from 67 million population, is 41 children in 2013 and 2023 [3]. The overall survival probability at 5 years of retinoblastoma in Thailand from nation-wide study was $73 \%$ [4]. However, there were different treatment outcomes among each center and region of the country. Currently, there are 7 centers that provide treatment for retinoblastoma in Thailand, 4 in Bangkok (capital city), and 3 in each part of Thailand, north, northeast, and south. Previous report from 3 cancer centers in northern, northeastern, and southern Thailand during 1990 and 2009, which included 75 retinoblastoma patients, showed the survival rate of $40 \%, 50 \%$, and $75 \%$, respectively [5]. Another report from a single institute of Bangkok during 1997 to 2006, which included 90 retinoblastoma patients, showed the survival rate of $85 \%$ [6]. Numerous studies worldwide, including Asia [7-30] and Thailand [4-6, 31-34], have described the clinical manifestations and treatment outcomes of retinoblastoma, but these studies did not use IAC, brachytherapy, or intravitreal chemotherapy as part of retinoblastoma treatment $[5-8,11-13,17-19,23-25$, 30-34]. Therefore, our study was aimed to fill in the gap in investigating clinical presentations and treatment outcomes of retinoblastoma in relation to the advent of recent treatment modalities in Thailand.

\section{Materials and Methods}

2.1. Patients and Study Design. This retrospective study was approved by the institutional review board of Faculty of Medicine, Ramathibodi Hospital (ID 02-60-56). We evaluated patients diagnosed with retinoblastoma between January 1, 2007, and December 31, 2018, at Ramathibodi Hospital, Bangkok, Thailand. Those with inadequate data on clinical presentation, tumor staging, and treatment modality were excluded. Demographic data included sex, ethnicity, age of onset, lag time from first presentation to diagnosis, laterality, family history of retinoblastoma, presenting signs and symptoms, follow-up time, and details of primary and adjunctive treatments were obtained from patients' medical record and analyzed statistically.

2.2. Staging and Treatment. Each patient underwent a complete ophthalmic examination under anesthesia, which included binocular indirect ophthalmoscopy with 360-degree indentation, Schiotz tonometer, and B-scan ultrasound. Fundus imaging and fluorescein angiography were performed using a wide-angle contact fundus camera (RetCam 3, Clarity Medical Systems, Inc., Pleasanton, CA, USA). Magnetic resonance imaging of the brain and orbits was performed in all patients to identify the presence of extraocular extension and intracranial tumors (trilateral retinoblastoma). Disease staging was classified according to International Retinoblastoma Staging System [35], and eyes with intraocular retinoblastoma were classified according to the International Classification of Retinoblastoma (ICRB) [36].

Treatment was selected based on disease stage, laterality, tumor location, visual prognosis, and input from the patients' families. For unilateral intraocular retinoblastoma, patients in ICRB groups A and B with macula- and/ or papilla-sparing tumors were locally treated with cryotherapy or transpupillary thermotherapy, depending on tumor location. For ICRB group B patients with macular and/or papillary involvement and patients in ICRB group $\mathrm{C}$, some patients of ICRB group D were treated with chemoreduction (CRD) or IAC. Risks and benefits of CRD and IAC were discussed in details with parents. Treatment decision was based on age of patients at the time of treatment, the feasibility of catheterization during IAC, and input from patients' families. For CRD, we followed the chemotherapy protocol from Children's Hospital of Philadelphia (CHOP) retinoblastoma [37]. The CRD regimen consisted of combined intravenous chemotherapy (carboplatin-etoposide-vincristine regimen), as well as local treatments such as cryotherapy, transpupillary thermotherapy, and plaque brachytherapy. Intravenous chemotherapy was given every 3-4 weeks for a total of six cycles. The detailed chemotherapy regimens are shown in Table 1. For IAC, we used melphalan, carboplatin, and topotecan, as described in our recent study [38]. Monthly examination under anesthesia was performed during the course of the treatment to evaluate treatment response. Primary enucleation was recommended in some unilateral ICRB group $\mathrm{D}$ and all unilateral ICRB group $\mathrm{E}$. In case of procedure refusal, IAC or IAC combined with CRD was proposed as an alternative treatment. Each enucleated eye was examined meticulously by a histopathologist trained in the evaluation of retinoblastoma globes to identify high-risk histopathological features, including postlaminar optic nerve involvement, choroidal involvement with a diameter greater than $3 \mathrm{~mm}$, anterior chamber involvement, and/or the involvement of both the optic nerve and choroid. Notably, for bilateral retinoblastoma patients, the primary treatment was CRD, with IAC reserved as an adjunctive treatment for cases of incomplete tumor response with CRD.

Intravitreal chemotherapy with melphalan or methotrexate was reserved for eyes with vitreous seeds, which poorly respond to systemic chemotherapy and/or IAC $[39,40]$. Safety-enhancement procedures as previously published, including ultrasonographic biomicroscopy surveillance of the injection site, lowering of intraocular pressure by paracentesis, cryotherapy at the injection site [41], and ocular surface irrigation with sterile water [42], were performed to prevent extraocular extension of the tumor.

For patients with orbital retinoblastoma, high-dose systemic chemotherapy (carboplatin-etoposide-vincristine regimen) was administered for 3-6 cycles, followed by enucleation or exenteration, external beam radiation therapy (EBRT), and adjuvant chemotherapy, for a total of 12 cycles, as previously reported [43]. 
TABLE 1: Retinoblastoma chemotherapy regimens [37, 43].

\begin{tabular}{|c|c|c|c|}
\hline \multirow{2}{*}{$\begin{array}{l}\text { Agents/course } \\
\text { interval }\end{array}$} & \multicolumn{3}{|c|}{ Regimens } \\
\hline & Standard dose $(\mathrm{BW}<12 \mathrm{~kg})$ & $\begin{array}{l}\text { Intensified dose for ICRB groups D and } \mathrm{E} \\
(\mathrm{BW}<12 \mathrm{~kg})\end{array}$ & $\begin{array}{l}\text { High dose for extraocular } \\
\text { retinoblastoma }\end{array}$ \\
\hline Vincristine & $\begin{array}{c}1.5 \mathrm{mg} / \mathrm{m}^{2} / \text { day on day } 1(0.05 \mathrm{mg} / \\
\mathrm{kg} / \text { day })\end{array}$ & $1.5 \mathrm{mg} / \mathrm{m}^{2} /$ day on day $1(0.05 \mathrm{mg} / \mathrm{kg} /$ day $)$ & $0.025 \mathrm{mg} / \mathrm{kg} /$ day on day 1 \\
\hline Etoposide & $\begin{array}{l}150 \mathrm{mg} / \mathrm{m}^{2} / \text { day on days } 1-2(5 \mathrm{mg} / \\
\mathrm{kg} / \text { day })\end{array}$ & $\begin{array}{c}180 \mathrm{mg} / \mathrm{m}^{2} / \text { day on days } 1-2(6 \mathrm{mg} / \mathrm{kg} / \\
\text { day })\end{array}$ & $12 \mathrm{mg} / \mathrm{kg} /$ day on days $1-2$ \\
\hline Carboplatin & $\begin{array}{l}560 \mathrm{mg} / \mathrm{m}^{2} / \text { day on day } 1(18.6 \mathrm{mg} / \\
\mathrm{kg} / \text { day })\end{array}$ & $\begin{array}{l}420 \mathrm{mg} / \mathrm{m}^{2} / \text { day on days } 1-2(14 \mathrm{mg} / \mathrm{kg} / \\
\text { day })\end{array}$ & $28 \mathrm{mg} / \mathrm{kg} /$ day on day 1 \\
\hline Course interval & $\begin{array}{c}\text { Continue every } 4 \text { weeks for a total } \\
\text { of six cycles }\end{array}$ & $\begin{array}{c}\text { Continue every } 4 \text { weeks for a total of six } \\
\text { cycles }\end{array}$ & $\begin{array}{c}\text { Continue every } 3 \text { weeks for a total of } \\
\text { six cycles }\end{array}$ \\
\hline
\end{tabular}

ICRB = International Classification of Retinoblastoma.

2.3. Statistical Analysis. Categorical variables were compared using Pearson chi-squared or Fisher's exact tests. The Kaplan-Meier method was used to estimate globe salvage and survival. The log-rank test was used to explore clinical characteristics and treatment modalities that affected globe salvage and survival curves. Univariate and multivariate Cox regression analyses were used to calculate unadjusted and adjusted hazard ratios. All statistical analyses were performed using Stata, version 15.0. $P<0.05$ was considered statistically significant.

\section{Results}

3.1. Patient Characteristics. Of 86 patients, 5 were excluded from the study due to incomplete data. Thus, 81 patients (124 eyes) were included in the analysis. Forty (49.4\%) patients were male. The median age at diagnosis was 8 months (range, 1-48 months). A total of $38(46.9 \%)$ patients had unilateral disease, while 43 (53.1\%) had bilateral disease. The median age of onset for bilateral disease was significantly lower than for unilateral disease (5 months vs 17 months, $P<0.001)$. The median lag time between symptom onset and visit to the oncology service was 6 weeks (range, 1-80 weeks). In our study, there were 4 patients (4.9\%) with familial retinoblastoma from 3 families. Two patients were siblings from the same family, and 2 patients from 2 families had parents with retinoblastoma.

Leukocoria was the most common presenting symptom ( $n=62$ patients, $76.5 \%$ ), followed by strabismus ( $n=8$ patients, 9.9\%), eye screening ( $n=4$ patients, $4.9 \%)$, buphthalmos $(n=3$ patients, $3.7 \%)$, orbital cellulitis $(n=2$ patients, $2.5 \%$ ), red eye ( $n=1$ patient, $1.2 \%$ ), and poor visual behavior ( $n=1$ patient, $1.2 \%$ ). Overall, $84 \%$ were treatmentnaïve, while $16 \%$ were treated initially from other centers. The overall median follow-up time was 38.4 months (range, 0.2-148.2 months), which were 4.7 months (range, 0.2-9.9 months) for dead patients and 46.4 months (range, 8.4-148.2 months) for survived patients.

3.2. Stage. Of the 81 patients, $88.9 \%$ ( $n=72$ patients, 115 eyes) had intraocular retinoblastoma, which was unilateral in $32(44.4 \%)$ patients and bilateral in $40(55.6 \%)$ patients. Of 115 eyes, 4 (3.5\%), 19 (16.5\%), 6 (5.2\%), 31 (27\%), and 55
(47.8\%) were classified as ICRB groups A, B, C, D, and E, respectively. For the unilateral tumor group (32 eyes, 27.8\%), $1(3.13 \%), 1(3.13 \%), 14(43.8 \%)$, and $16(50 \%)$ were classified as ICRB groups B, C, D, and E, respectively. For the bilateral tumor group (83 eyes, $72.2 \%), 4$ (4.8\%), 18 (21.7\%), 5 (6\%), 17 (20.5\%), and 39 (47\%) were classified as the ICRB groups A, B, C, D, and E, respectively. Notably, the majority of eyes with intraocular retinoblastoma in our study exhibited advanced stage of disease, which was classified as ICRB groups D and $\mathrm{E}$ in 86 eyes (74.8\%).

Extraocular extension, diagnosed on the basis of clinical and radiological manifestations, was found in 9 of $81 \mathrm{pa}-$ tients (11.1\%). Of these nine patients, four $(44.4 \%)$ had overt orbital disease, while $5(55.6 \%)$ had radiologically detected extraocular extension. Lumbar puncture and bone marrow biopsy were performed in all patients with extraocular tumors. No patients had central nervous system or distant metastasis at initial presentation.

There were no statistically significant differences in median age of onset, median lag time, sex, and laterality between intraocular and extraocular tumor groups.

3.3. Treatment. Detailed treatment modalities of the studied eyes are shown in Tables 2 and 3. For the unilateral intraocular tumor group (32 eyes, 27.8\%), 23 eyes (71.9\%) were treated with globe salvage therapy. Primary enucleation was performed in 9 eyes (28.1\%). Secondary enucleation was performed in 11 eyes (34.4\%). For the bilateral intraocular tumor group (83 eyes, $72.2 \%), 69$ eyes (83.1\%) were treated with globe salvage therapy. Primary enucleation was performed in 14 eyes (16.9\%). Secondary enucleation was performed in 21 eyes (25.3\%). High-risk pathological features were found in 12 enucleated patients $(21.8 \%)$, which all received postenucleation adjuvant chemotherapy. There was no local recurrence or systemic metastasis in this group of patients at a median follow-up time of 27.4 months (range, 0.4-107.7 months).

3.4. Treatment Outcome and Survival Outcomes. With the availability of new treatment modalities at our center, the overall globe salvage rate for the intraocular retinoblastoma group was 51.7\% (groups A and C, 100\%; group B, 94.7\%; 
TABLE 2: Treatment modalities and globe salvage rates for intraocular tumor according to International Classification of Retinoblastoma (ICRB).

\begin{tabular}{|c|c|c|c|c|c|c|c|c|c|c|}
\hline \multirow{3}{*}{$\begin{array}{l}\text { Treatment modalities, } \\
n=115\end{array}$} & \multicolumn{10}{|c|}{ ICRB group, eyes (globe salvage, \%) } \\
\hline & \multicolumn{2}{|c|}{ A } & \multicolumn{2}{|c|}{ B } & \multicolumn{2}{|c|}{$\mathrm{C}$} & \multicolumn{2}{|c|}{$\mathrm{D}$} & \multicolumn{2}{|c|}{$\mathrm{E}$} \\
\hline & Unilateral & Bilateral & Unilateral & Bilateral & Unilateral & Bilateral & Unilateral & Bilateral & Unilateral & Bilateral \\
\hline CRD & - & $\begin{array}{c}4 \\
(100 \%)\end{array}$ & $1(100 \%)$ & $\begin{array}{c}9 \\
(100 \%)\end{array}$ & - & $\begin{array}{c}2 \\
(100 \%)\end{array}$ & - & $\begin{array}{c}9 \\
(66.7 \%)\end{array}$ & $2(0 \%)$ & $\begin{array}{c}19 \\
(47.4 \%)\end{array}$ \\
\hline CRD + plaque & - & - & - & $\begin{array}{c}2 \\
(100 \%)\end{array}$ & $1(100 \%)$ & - & - & - & - & \\
\hline CRD + EBRT & - & - & - & $\begin{array}{c}1 \\
(100 \%)\end{array}$ & - & - & - & $1(0 \%)$ & - & \\
\hline CRD + IAC & - & - & - & $\begin{array}{c}2 \\
(100 \%)\end{array}$ & - & $\begin{array}{c}1 \\
(100 \%)\end{array}$ & $4(75 \%)$ & $\begin{array}{c}4 \\
(100 \%)\end{array}$ & $3(0 \%)$ & $\begin{array}{c}6 \\
(33.3 \%)\end{array}$ \\
\hline CRD + IAC + IVT & - & - & - & $\begin{array}{c}1 \\
(100 \%)\end{array}$ & - & $\begin{array}{c}2 \\
(100 \%)\end{array}$ & $1(100 \%)$ & - & - & \\
\hline CRD + IAC + plaque & - & - & - & - & - & - & $4(75 \%)$ & $1(0 \%)$ & - & \\
\hline CRD + IVT + plaque & - & - & - & $2(50 \%)$ & - & - & - & - & - & \\
\hline CRD + IAC + IVT + plaque & - & - & - & $\begin{array}{c}1 \\
(100 \%)\end{array}$ & - & - & $1(0 \%)$ & - & - & \\
\hline IAC & - & - & - & - & - & - & $1(0 \%)$ & $\begin{array}{c}1 \\
(100 \%)\end{array}$ & $3(67.7 \%)$ & $1(0 \%)$ \\
\hline IAC + IVT & - & - & - & - & - & - & - & - & $1(100 \%)$ & \\
\hline IAC + IVT + plaque & - & - & - & - & - & - & $1(0 \%)$ & - & & \\
\hline $\begin{array}{l}\text { Primary enucleation (in our } \\
\text { center/from referral } \\
\text { hospital) }\end{array}$ & - & - & - & - & - & - & $2(1 / 1)$ & $1(0 / 1)$ & $7(7 / 0)$ & $13(8 / 5)$ \\
\hline $\begin{array}{l}\text { Secondary enucleation (in } \\
\text { our center/from referral } \\
\text { hospital) }\end{array}$ & - & - & - & 1 & - & - & $5(5 / 0)$ & $5(5 / 0)$ & $6(6 / 0)$ & $\begin{array}{l}15(14 / \\
1)\end{array}$ \\
\hline Total & 0 & $\begin{array}{c}4 \\
(100 \%)\end{array}$ & $1(100 \%)$ & $\begin{array}{c}18 \\
(94.4 \%)\end{array}$ & $1(100 \%)$ & $\begin{array}{c}5 \\
(100 \%)\end{array}$ & $14(50 \%)$ & $\begin{array}{c}17 \\
(64.7 \%)\end{array}$ & $\begin{array}{c}16 \\
(18.8 \%)\end{array}$ & $\begin{array}{c}39 \\
(28.2 \%)\end{array}$ \\
\hline
\end{tabular}

ICRB = International Classification of Retinoblastoma; $C R D=$ chemoreduction; IAC = intra-arterial chemotherapy; EBRT = external beam radiation therapy; IVT = intravitreal chemotherapy.

group D, 58\%; and group E, 25\%). Regarding to laterality, the globe salvage rate was $37.5 \%$ in the unilateral intraocular retinoblastoma group (group B, 100\%; group C, $100 \%$; group D, $50 \%$; and group E, $18.8 \%$ ) and $57.8 \%$ for the bilateral intraocular retinoblastoma group (group A, 100\%; group B, 94.4\%; group C, $100 \%$; group D, 64.7\%; and group E, $28.2 \%$ ). Five patients died in our study. The overall survival rate was $93.8 \%$. The detailed characteristics and treatment course of deceased patients are summarized in Supplement Table 1.

Kaplan-Meier analysis included 104 of 115 eyes with intraocular tumors, 29 eyes of unilateral intraocular tumor, and 75 eyes of bilateral intraocular tumor (Figure 1(a)); the remaining eyes were excluded because enucleation was initially performed at other center. The probabilities of globe salvage for unilateral and bilateral groups were $54 \%$ and $68 \%$ at 1 year, $41 \%$ and $64 \%$ at 2 years, and $34 \%$ and $62 \%$ at 5 years, respectively. Figures 1(b) and 1(c) show the probability of globe salvage based on ICRB classification. Kaplan-Meier analysis showed a 5-year survival rate of 93.5\%.

The hazard ratios of globe salvage according to patient characteristics and treatment modalities are shown in Figure 2. For all eye analysis (Figure 2(a)), Cox regression analysis showed that the bilateral group had better globe salvage outcome (HR: $0.46, P=0.007)$. However, there were no statistically significant differences in globe salvage outcome with respect to other characteristics and treatment modalities by all analysis (all eyes, unilateral tumor and bilateral tumor) (Figures 2(a) and 2(c)).

\section{Discussion}

Several studies have shown that the clinical characteristics and treatment outcomes of retinoblastoma vary worldwide (Table 4). In this study, we investigated the clinical presentations and outcomes of retinoblastoma in relation to the advent of new multimodal treatments in Thailand. The median age of onset was 8 months (range, 1-48 months), which was comparable to a study from Japan (13 months) [19]. However, an older age of onset has been reported in studies from other nations, ranging from 13 to 36 months $[6-8,10,12,13,17,19,23-25,27,29,30,45-49,51]$. Although our study showed an approximately equal proportion of unilateral and bilateral disease $(46.9 \%$ and $53.1 \%$ for unilateral and bilateral disease, respectively), studies from the United States [52] and India [8] have revealed higher rates of unilateral disease than bilateral disease. Similar to other studies $[6-8,12,13,17,22-25,53,54]$, the median age at diagnosis in our patients with bilateral disease was 


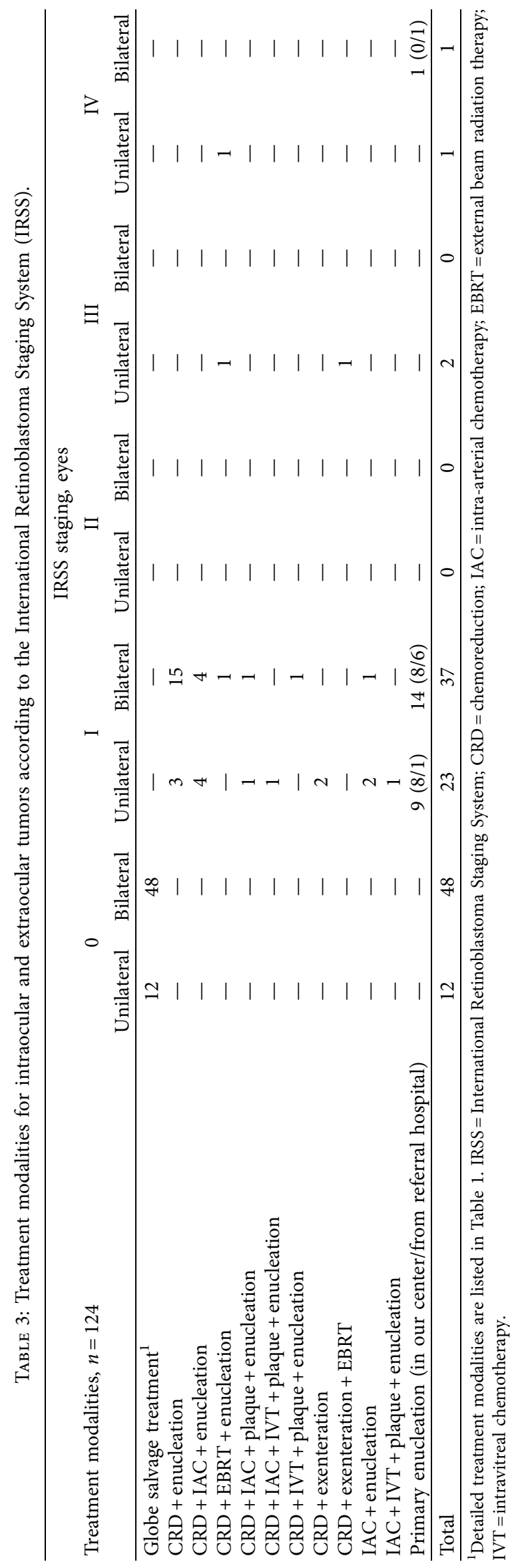




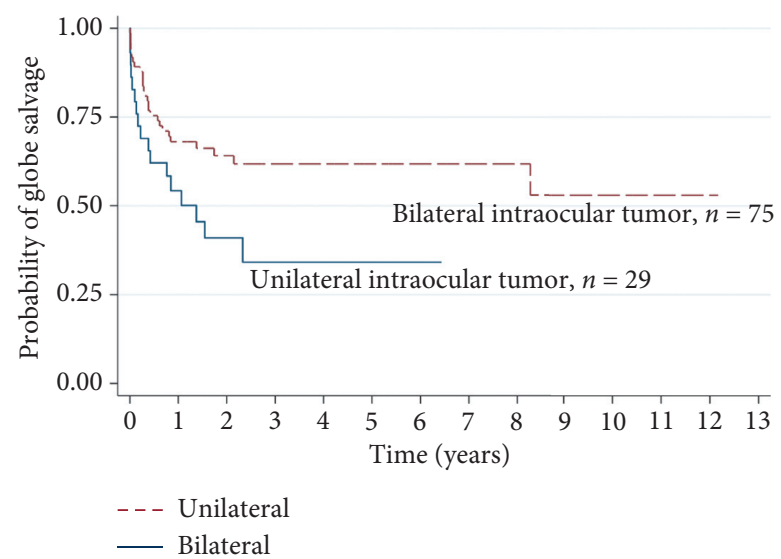

(a)

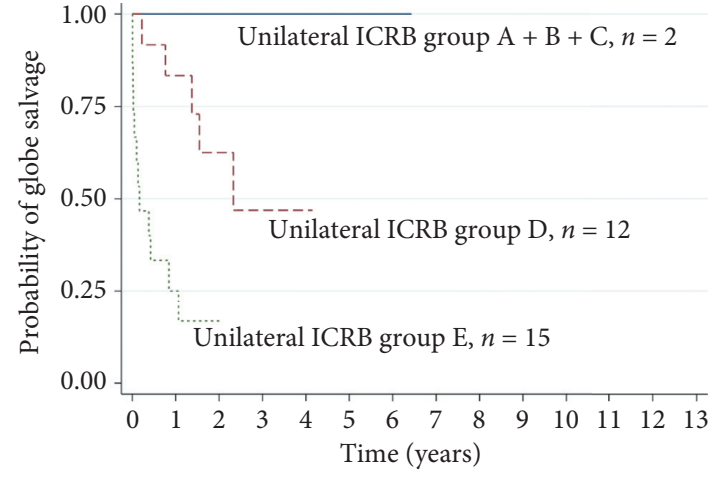

(b)

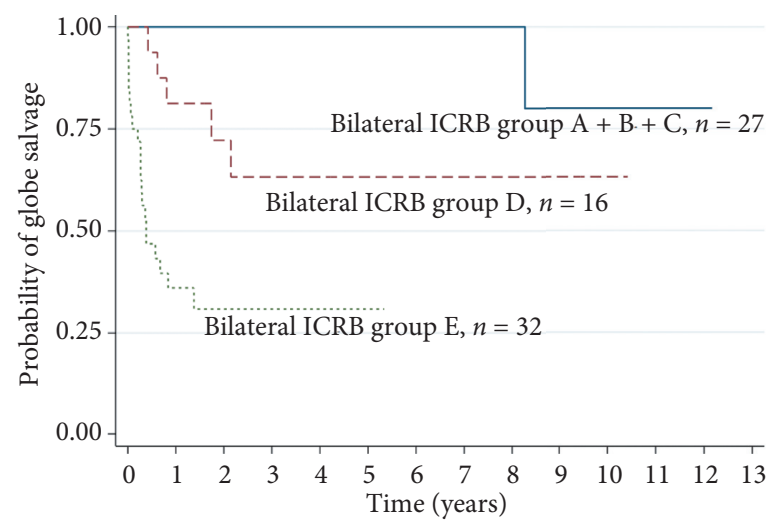

(c)

Figure 1: Kaplan-Meier survival analysis of globe salvage in intraocular tumors: (a) including all eyes (unilateral vs. bilateral); (b, c) unilateral and bilateral: based on the International Classification of Retinoblastoma (ICRB).

Hazard ratio $(95 \% \mathrm{CI})$

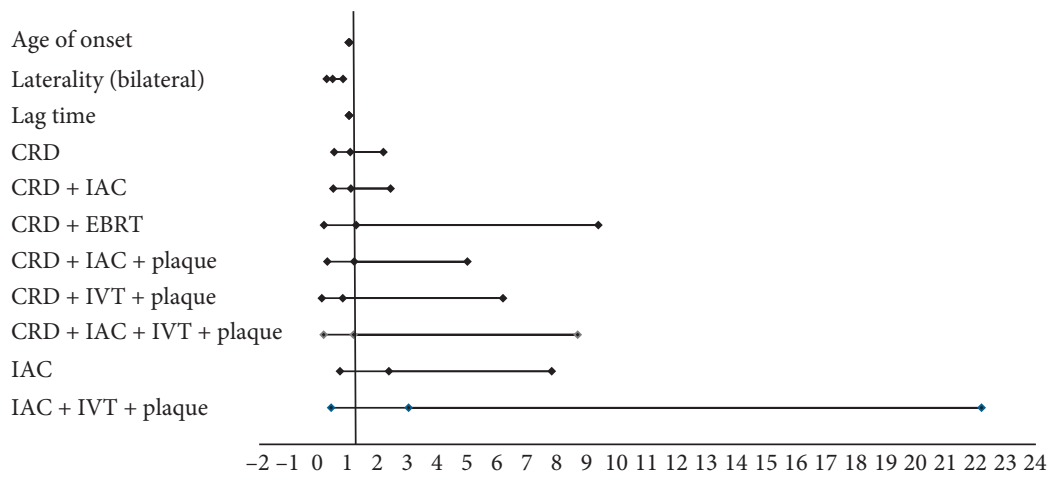

$1.01(0.99,1.03)$

$0.46(0.26,0.81)$

$1.01(1.00,1.02)$

$1.05(0.51,2.16)$

$1.07(0.48,2.40)$

$1.25(0.17,9.35)$

$1.18(0.28,4.97)$

$0.80(0.10,6.16)$

$1.16(0.16,8.66)$

$2.34(0.71,7.79)$

$3.00(0.41,22.18)$

(a)

Figure 2: Continued. 


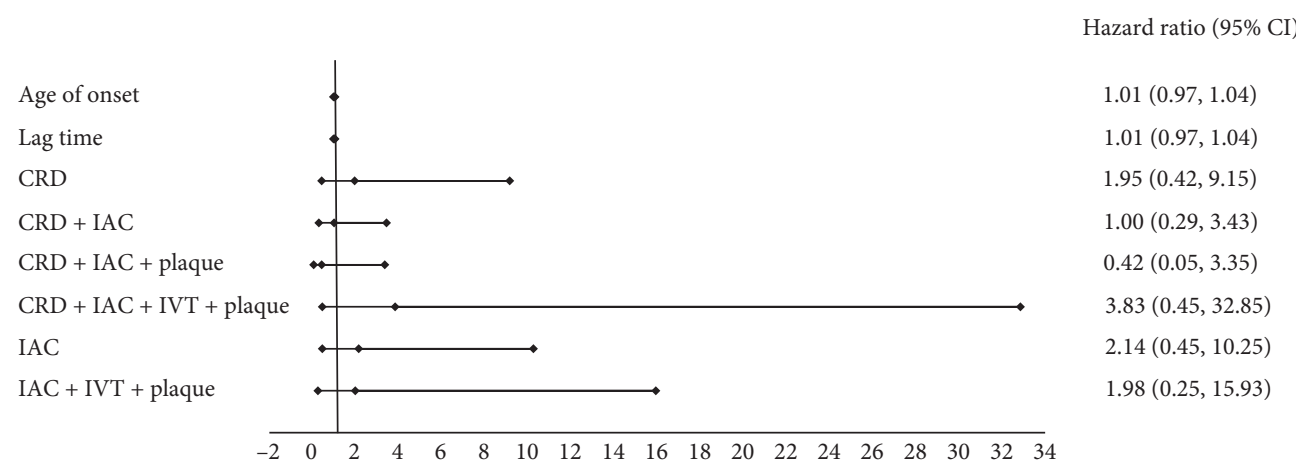

(b)

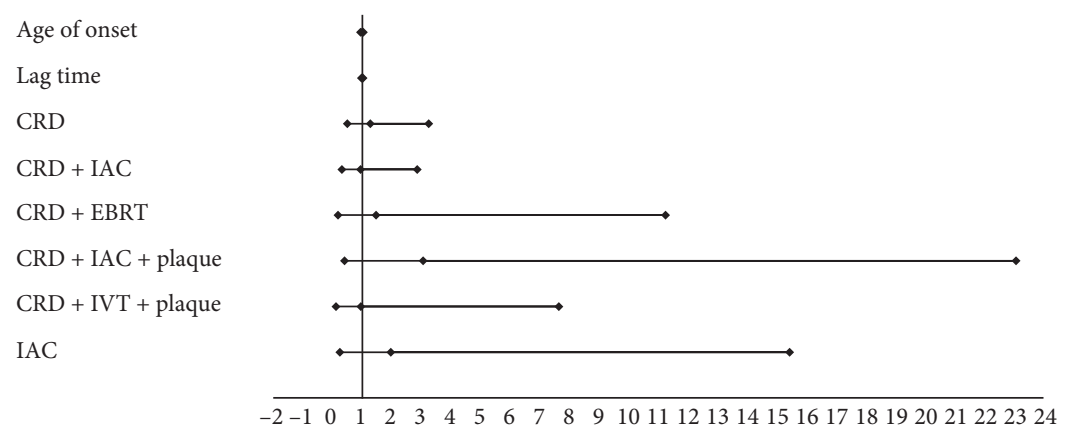

Hazard ratio $(95 \% \mathrm{CI})$

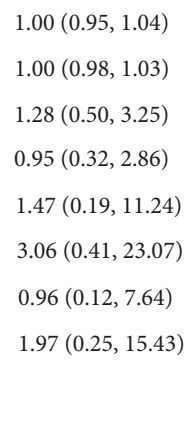

(c)

FIgURE 2: Hazard ratio of globe salvage according to patient characteristics and treatment modalities: (a) including all eyes (unilateral vs. bilateral); (b, c) unilateral and bilateral: based on the International Classification of Retinoblastoma (ICRB). CRD = chemoreduction; $\mathrm{IAC}=$ intra-arterial chemotherapy; EBRT = external beam radiation therapy; IVT = intravitreal chemotherapy.

significantly lower than that of patients with unilateral disease ( 5 months vs 17 months, $P<0.001$ ). The median lag time from first presentation until detection by an ocular oncologist was 5 weeks (range, 1-80 weeks), which was shorter than the median of 3 months reported in a study from India [13]. The shorter lag time may reflect increasing public awareness and improvements in our referral systems. No sex bias was noted in our patients, which was consistent with many previous studies $[8,54]$. However, a male predominance has been reported in some studies [13], which might be attributed to the lack of attention to female children in those countries, particularly in rural areas [13]. Similar to several prior studies $[5,7-10,12,13,17,19,23-25$, $27,29,55]$, the most common presenting symptom in our study was leukocoria $(76.5 \%)$, followed by strabismus (9.9\%). As an initial sign, proptosis was found in $40 \%$ of cases in a study from Nepal [30], whereas none of our patients exhibited proptosis at their initial visit. Most retinoblastoma patients in developed countries exhibit intraocular tumors at presentation, while patients with extraocular tumors are rare (3\%-4\%) $[19,56]$. In contrast, extraocular extension is commonly found in developing countries in Asia, Africa, and South America (approximately $27 \%-69 \%$ ) $[10,13,30,45,48,49]$. In our study, extraocular retinoblastoma was found in $9.8 \%$ of all cases. Our analysis showed that the median lag time was not correlated with the presence of extraocular extension. This might be related to the limited number of cases with extraocular extension in our study. Among patients with intraocular retinoblastoma, the number of patients presenting at advanced stages (ICRB groups D or E) are higher in developing countries including Thailand $[6-8,10,12-14,27,29,48]$. Therefore, a major challenge in our country is the implementation of an early detection program to minimize the progression of retinoblastoma to advanced stages and allow for the treatment at earlier stages of disease and have better treatment outcomes. The main goals of retinoblastoma treatment, in descending order of importance, are to save the life, globe, and vision of the patient. In order to achieve the treatment goals, we treated our patients based on laterality, tumor staging, tumor location, visual potential, and input from patients' families.

The role of systemic chemotherapy in preventing pinealoblastoma and second neoplasm in germline retinoblastoma is controversial [57-59]. We used VEC regimen in our study for bilateral retinoblastoma patients and found that no patients in our study developed pinealoblastoma or second neoplasm during our study period. However, 5 patients died in our study, and 3 were chemotherapy-related (febrile neutropenia, chemotherapy toxicity, and chemotherapy-induced sAML). Therefore, the risks and benefits of systemic chemotherapy should be reviewed with family members before the initiation of treatment. Further studies regarding systemic chemotherapy-related complications and its role in preventing pinealoblastoma or second neoplasms 


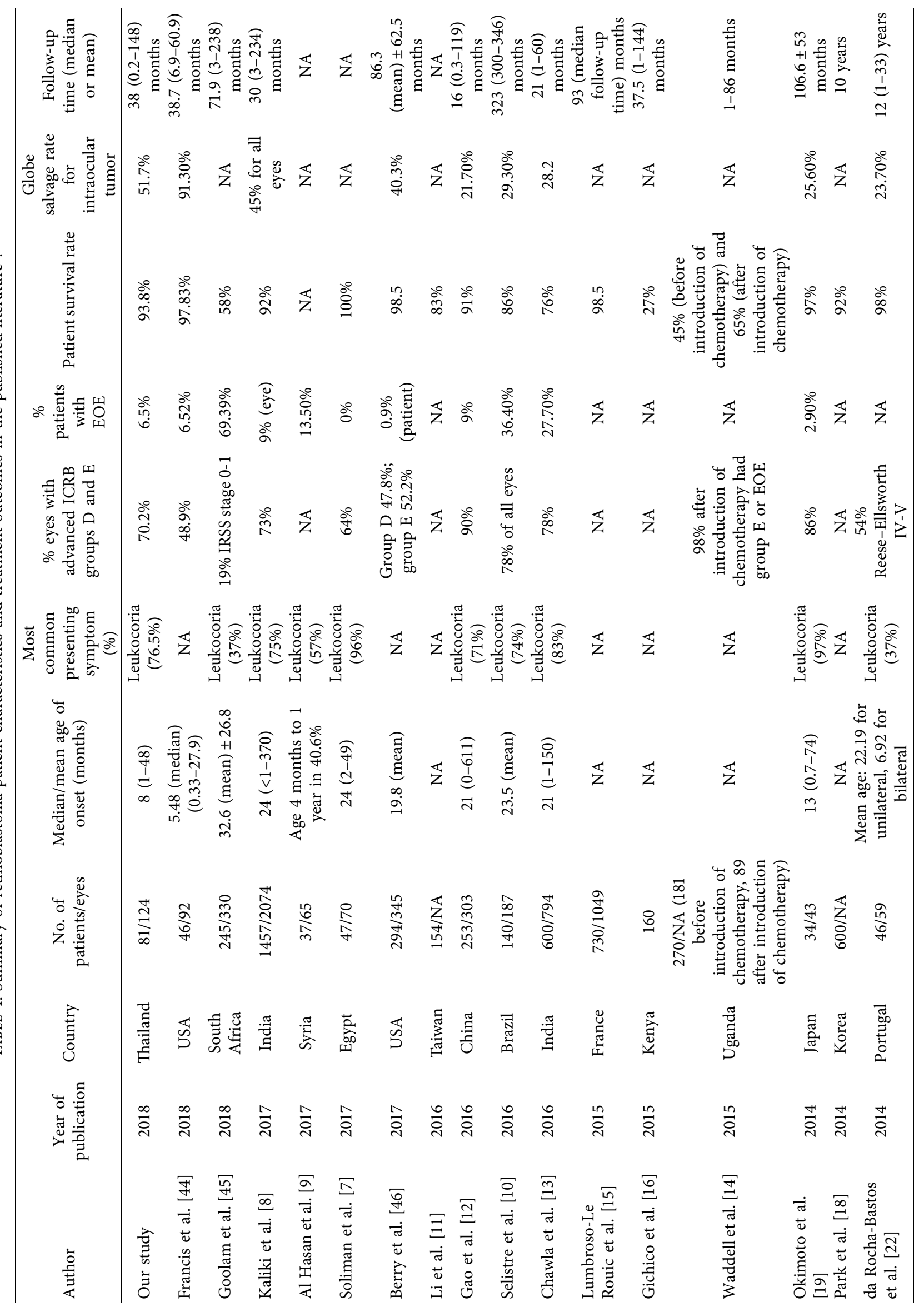




\begin{tabular}{|c|c|c|c|c|c|c|c|c|c|c|c|c|c|}
\hline 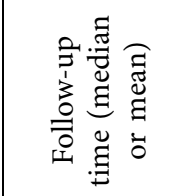 & $\overleftrightarrow{z}$ & 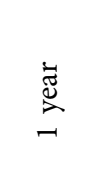 & 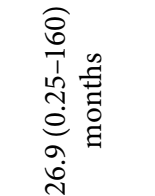 & 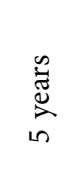 & $\overleftrightarrow{Z}$ & 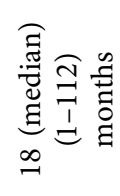 & 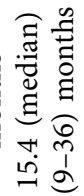 & 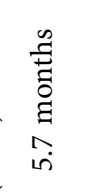 & 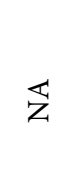 & 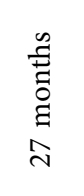 & 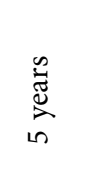 & 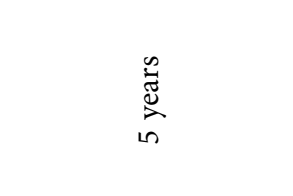 & 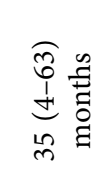 \\
\hline 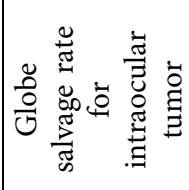 & 艺 & $\overleftrightarrow{Z}$ & 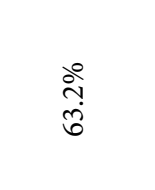 & 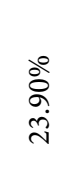 & 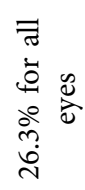 & $\overleftrightarrow{z}$ & $\overleftrightarrow{z}$ & $\overleftrightarrow{z}$ & $\overleftrightarrow{z}$ & 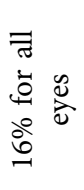 & $\overleftrightarrow{z}$ & $\overleftrightarrow{Z}$ & 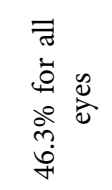 \\
\hline 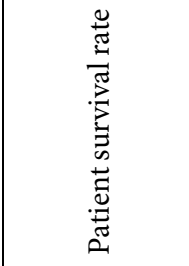 & $\stackrel{\infty}{\infty}$ & 究 & $\overleftrightarrow{Z}$ & $\stackrel{\circ}{\partial}$ & $\overleftrightarrow{Z}$ & $\stackrel{\text { సे }}{\circ}$ & 宫 & ठ্ণ & $\overleftrightarrow{z}$ & 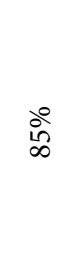 & 웅 & 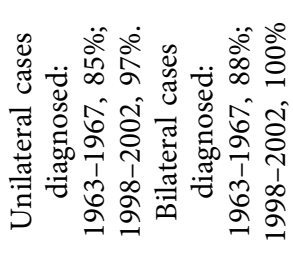 & ลे \\
\hline 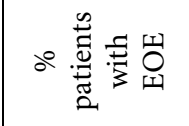 & $\overleftrightarrow{z}$ & $\overleftrightarrow{Z}$ & $\overleftrightarrow{Z}$ & ठ̊ & $\overleftrightarrow{z}$ & ठิ & ㅇํㅁ & $\stackrel{\circ}{\stackrel{0}{2}}$ & $\overleftrightarrow{z}$ & $\stackrel{\circ}{\stackrel{్}{~}}$ & $\overleftrightarrow{z}$ & $\overleftrightarrow{Z}$ & $\begin{array}{l}\text { ڤे } \\
\text { 仓े }\end{array}$ \\
\hline 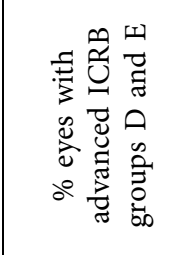 & $\overleftrightarrow{z}$ & $\overleftrightarrow{z}$ & 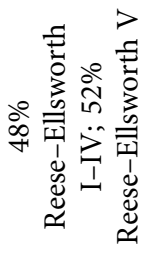 & $\begin{array}{l}\stackrel{0}{\infty} \\
\infty \\
\infty\end{array}$ & $\overleftrightarrow{Z}$ & 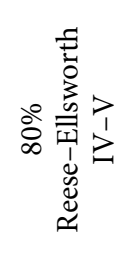 & $\mathbb{z}$ & 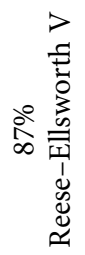 & $\overleftrightarrow{z}$ & 용 & $\overleftrightarrow{z}$ & $\overleftrightarrow{Z}$ & 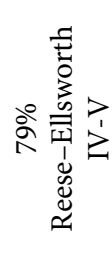 \\
\hline 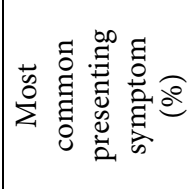 & $\overleftrightarrow{z}$ & 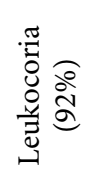 & 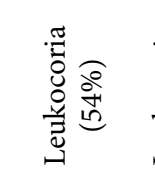 & 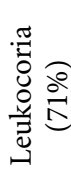 & 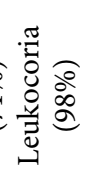 & $\overleftrightarrow{Z}$ & 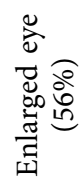 & 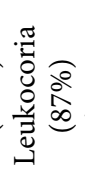 & 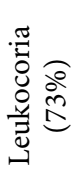 & $\overleftrightarrow{z}$ & $\overleftrightarrow{Z}$ & $\overleftrightarrow{Z}$ & 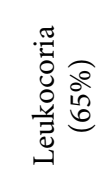 \\
\hline 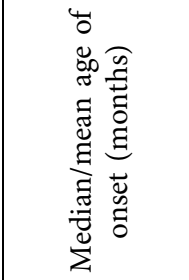 & 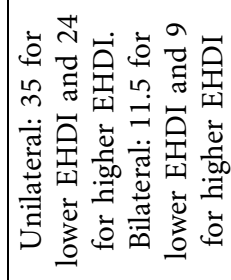 & 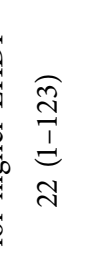 & 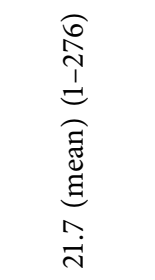 & 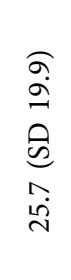 & 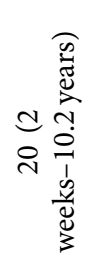 & 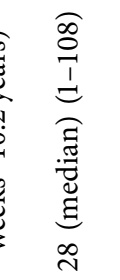 & 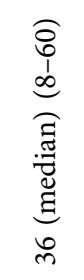 & $\begin{array}{l}m \\
\stackrel{m}{=} \\
+1 \\
\stackrel{+}{+} \\
\stackrel{+}{N}\end{array}$ & 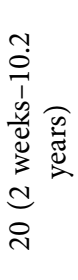 & 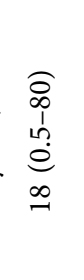 & $\overleftrightarrow{z}$ & $\overleftrightarrow{Z}$ & $\begin{array}{l}a \\
\stackrel{0}{0} \\
1 \\
\stackrel{1}{d} \\
\infty \\
-1\end{array}$ \\
\hline 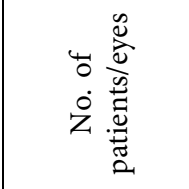 & $\begin{array}{l}\hat{N} \\
\hat{N} \\
\infty \\
\stackrel{y}{\gamma}\end{array}$ & 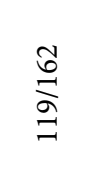 & $\underset{⿱}{\stackrel{\Xi}{E}}$ & $\frac{\hat{\sigma}}{\vec{n}}$ & $\frac{\hat{n}}{a}$ & 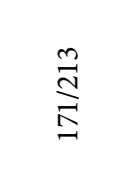 & $\stackrel{\vec{n}}{\stackrel{\omega}{N}}$ & 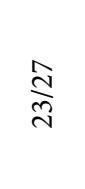 & 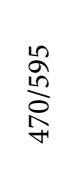 & 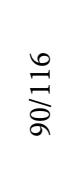 & 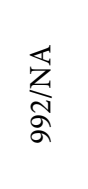 & 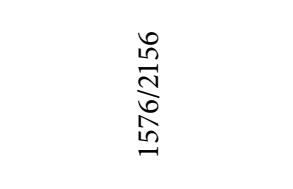 & $\underset{\widetilde{J}}{\stackrel{\vec{J}}{二}}$ \\
\hline $\begin{array}{l}\hat{E} \\
0\end{array}$ & 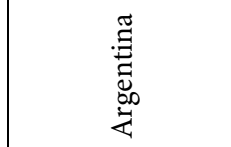 & 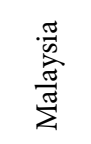 & 㞼 & 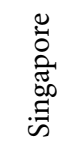 & 馬 & 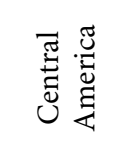 & 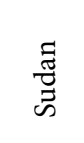 & $\underset{\widetilde{J}}{\tilde{J}}$ & 苞 & 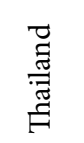 & 㤐 & 营. & $\begin{array}{l}\widehat{\overrightarrow{\vec{u}}} \\
\stackrel{\vec{\Xi}}{\Xi}\end{array}$ \\
\hline 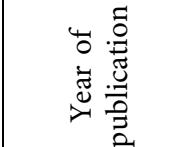 & 弚 & $\underset{⿱ 乛}{\vec{N}}$ & 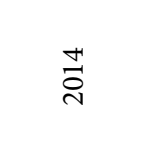 & $\stackrel{m}{\vec{\sim}}$ & 곡 & 귝 & $\overrightarrow{\vec{i}}$ & $\stackrel{\circ}{\stackrel{\text { స }}{~}}$ & 윰 & ڤ્ণ & ڤ્ণ & \&્రి & \\
\hline 泀 & 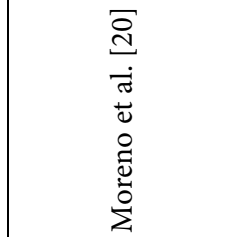 & 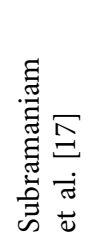 & 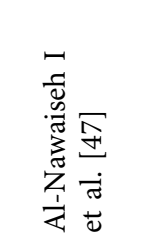 & 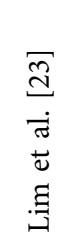 & 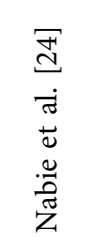 & 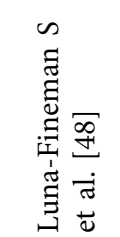 & 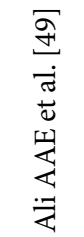 & 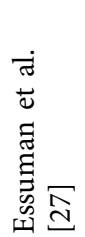 & 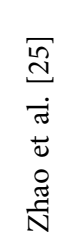 & 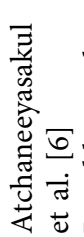 & 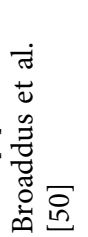 & 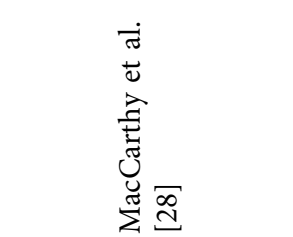 & 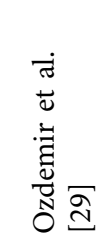 \\
\hline
\end{tabular}




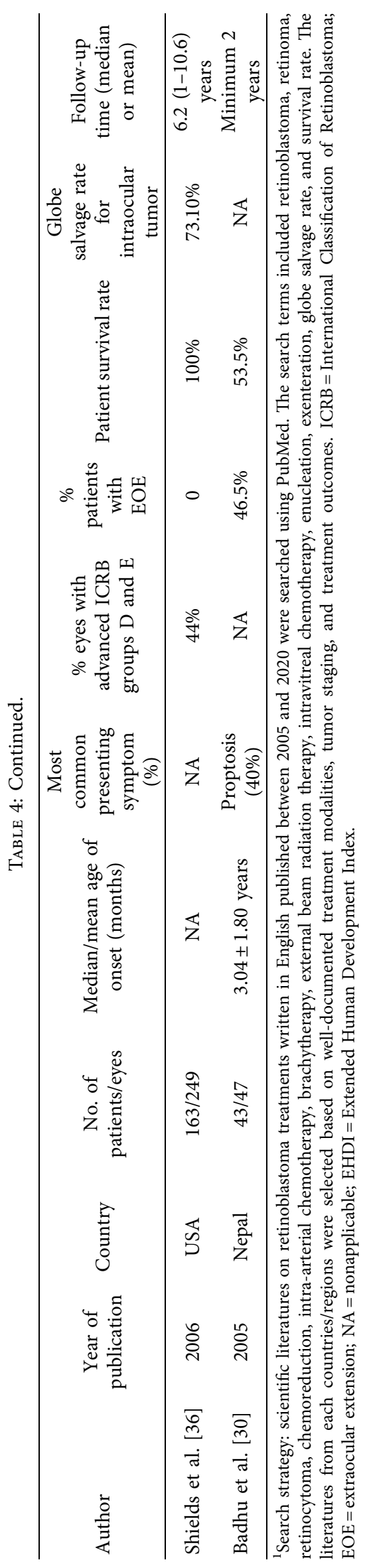


are needed to identify the true risks and benefits of systemic chemotherapy in the treatment of bilateral retinoblastoma.

Because of the greater proportion of advanced retinoblastoma cases in our series, the overall globe salvage rate was $51.7 \%$, which was much lower than that observed in developed nations $[36,44,56]$. However, globe salvage was achieved in $100 \%$ of patients in ICRB groups A and C, in $94.7 \%$ of patients in group B, in $58 \%$ of patients in group D, and in $25 \%$ of patients in group $\mathrm{E}$. This was comparable to that in developed nations [36]. There was no significant association between globe salvage outcome and treatment modalities, as shown in Figure 2. This may be the result of the small sample sizes within the treatment groups.

Primary enucleation remains a life-saving intervention in advanced unilateral retinoblastoma (ICRB groups D and E) because it can effectively cure the disease, save the patients' life, reduce the risk of metastasis, reduce the number of subsequent follow-up visits, and avoid possible side effects of systemic chemotherapy or IAC. The pathological examination of enucleated eye by histopathologist trained in the evaluation of retinoblastoma globe is crucial to identify highrisk pathological features. Graduated intensity of postenucleation adjuvant chemotherapy should be given based on pathological study of each enucleated eye [60]. In Thailand and some other countries, especially in Asia, primary enucleation may be unacceptable to many patients' families. Strong advice of primary enucleation to these families can lead to treatment refusal, abandonment of the treatment, and subsequently loss of follow-up. In this situation globe salvage treatment may keep patients' families on the treatment track and make secondary enucleation more acceptable. A study from Malaysia [51] reported that most families refuse the treatment, as well as any further management, upon counseling in favor of enucleation. At our center, globe salvage treatment was offered as an alternative treatment for patients with unilateral ICRB group $\mathrm{D}$ or $\mathrm{E}$ whose families strongly refused enucleation. This was performed with the aim of preventing families from abandoning treatment altogether. All of them were informed of and accepted the risk of extraocular extension and distant metastasis. Ultimately, there was no abandonment of treatment in this group. In our study, 30 eyes had unilateral intraocular retinoblastoma group D or E. Nine eyes (30\%) underwent primary enucleation, while twenty-one eyes (70\%) underwent primary systemic chemoreduction and/or IAC with various adjuvant treatment modalities (Table 2). The globe salvage rate was 10 eyes $(33.3 \%)$ with the median follow-up time of 26 months, and neither local recurrence nor distant metastasis was observed. However, 11 eyes (36.7\%) did not respond to treatments and eventually underwent secondary enucleation as permitted by their families.

As shown in Table 4, the survival rate of retinoblastoma patients in internationally published data varies from $26 \%$ to $100 \%$, with developed nations tending to exhibit more favorable survival outcomes than developing nations. The primary influencing factor of disease-related mortality was extraocular extension, which was generally attributed to late presentation and delay in the referral system. In our series, the overall survival rate of $93.8 \%$ was consistent with the 5year survival estimated using Kaplan-Meier analysis. Of the five deaths recorded in our series, two were related to extraocular disease, and the remaining three were due to chemotherapy-related complications (febrile neutropenia, chemotherapy toxicity, and sAML).

The major limitation of this study was its limited scope and sample size; all data were obtained from a single referral center in Bangkok, which may not entirely represent retinoblastoma patients in Thailand. A multicenter national study and a national system of retinoblastoma registration are required to establish a nation-wide picture of this disease. Education of the public and primary health care providers, along with the implementation of a retinoblastoma screening program, should be promoted to enable earlier detection of retinoblastoma. This would enable patients to achieve better treatment outcomes. In addition, proper retinoblastoma management requires multidisciplinary cooperation, which includes medical personals, nurses, ocularists, ocular oncologists, pediatric oncologists, interventional neuroradiologists, neurosurgeons, anesthesiologists, and ocular pathologists. Because these specialized providers are not available in many areas of the country, comprehensive referral centers may provide a solution for the enhanced provision of retinoblastoma care in Thailand.

\section{Conclusions}

In summary, we have shown the clinical presentation and treatment outcomes of retinoblastoma patients who underwent recent multimodal treatments at our center, spanning a period of 12 years. Although the treatment of retinoblastoma remains a complex challenge in Thailand, the recent availability of advanced treatment modalities at our center has enhanced our capacity to save lives and has increased the likelihood of globe salvage. The current study fills a gap in the existing literature by reporting clinical presentations and outcomes of retinoblastoma with the recent multimodal treatments in Thailand.

\section{Data Availability}

All the data used to support the findings of this study are included within the article and are available from the corresponding author by a reasonable request.

\section{Disclosure}

The funders had no role in design of the study, in the data collection, analysis, or interpretation of data, in the decision to publish, or in the writing of the manuscript.

\section{Conflicts of Interest}

The authors declare that there are no conflicts of interest pertaining to the publication of this article. 


\section{Acknowledgments}

This work was supported by the Ramathibodi Foundation and Children Cancer Fund under the Patronage of $\mathrm{HRH}$ Princess Soamsawali.

\section{Supplementary Materials}

Supplement Table 1. The detailed characteristics and treatment course of dead patients. (Supplementary Materials)

\section{References}

[1] D. H. Abramson, "Retinoblastoma in the 20th century: past success and future challenges the Weisenfeld lecture," Investigative Ophthalmology \& Visual Science, vol. 46, pp. 2683-2691, 2005.

[2] T. Kivela, "The epidemiological challenge of the most frequent eye cancer: retinoblastoma, an issue of birth and death," British Journal of Ophthalmology, vol. 93, no. 9, pp. 1129-1131, 2009.

[3] R. H. Usmanov and T. Kivelä, "Predicted trends in the incidence of retinoblastoma in the Asia-Pacific region," AsiaPacific Journal of Ophthalmology, vol. 3, no. 3, pp. 151-157, 2014.

[4] S. Wiangnon, G. Veerakul, I. Nuchprayoon et al., "Childhood cancer incidence and survival 2003-2005, Thailand: study from the Thai Pediatric Oncology Group," Asian Pacific Journal of Cancer Prevention: APJCP, vol. 12, no. 9, pp. 2215-2220, 2011.

[5] P. Wongmas, A. Jetsrisuparb, P. Komvilaisak et al., "Incidences, trends and long term outcomes of retinoblastoma in three cancer registries, Thailand," Asian Pacific Journal of Cancer Prevention, vol. 16, no. 16, pp. 6899-6902, 2015.

[6] L.-o. Atchaneeyasakul, C. Wongsiwaroj, M. Uiprasertkul, K. Sanpakit, K. Thephamongkhol, and A. Trinavarat, "Prognostic factors and treatment outcomes of retinoblastoma in pediatric patients: a single-institution study," Japanese Journal of Ophthalmology, vol. 53, no. 1, pp. 35-39, 2009.

[7] S. E. Soliman, W. Eldomiaty, M. B. Goweida, and A. Dowidar, "Clinical presentation of retinoblastoma in Alexandria: a step toward earlier diagnosis," Saudi Journal of Ophthalmology, vol. 31, no. 2, pp. 80-85, 2017.

[8] S. Kaliki, A. Patel, S. Iram, G. Ramappa, A. Mohamed, and V. A. R. Palkonda, "Retinoblastoma in India," Retina, vol. 39, no. 2, pp. 379-391, 2019.

[9] A. Al Hasan, R. Murad, K. Zaid et al., "Epidemiological characteristics of retinoblastoma in children attending almouassat university hospital, damascus, Syria, 2012-2016," Asian Pacific Journal of Cancer Prevention, vol. 18, pp. 421424, 2017.

[10] S. G. A. Selistre, M. K. Maestri, P. Santos-Silva et al., "Retinoblastoma in a pediatric oncology reference center in Southern Brazil," BMC Pediatr, vol. 16, p. 48, 2016.

[11] S.-Y. Li, S. C.-C. Chen, C.-F. Tsai, S.-M. Sheu, J.-J. Yeh, and C.-B. Tsai, "Incidence and survival of retinoblastoma in Taiwan: a nationwide population-based study 1998-2011," British Journal of Ophthalmology, vol. 100, no. 6, pp. 839-842, 2016.

[12] J. Gao, J. Zeng, B. Guo et al., "Clinical presentation and treatment outcome of retinoblastoma in children of South Western China," Medicine (Baltimore), vol. 95, 2016.
[13] B. Chawla, F. Hasan, R. Azad et al., "Clinical presentation and survival of retinoblastoma in Indian children," British Journal of Ophthalmology, vol. 100, no. 2, pp. 172-178, 2016.

[14] K. M. Waddell, K. Kagame, A. Ndamira et al., "Improving survival of retinoblastoma in Uganda," British Journal of Ophthalmology, vol. 99, no. 7, pp. 937-942, 2015.

[15] L. Lumbroso-Le Rouic, A. Savignoni, C. Levy-Gabriel et al., "Treatment of retinoblastoma: the Institut Curie experience on a series of 730 patients (1995 to 2009)," Journal Français d'Ophtalmologie, vol. 38, no. 6, pp. 535-541, 2015.

[16] E. N. Gichigo, M. M. Kariuki-Wanyoike, K. Kimani, and M. M. Nentwich, "Retinoblastom in kenia," Der Ophthalmologe, vol. 112, no. 3, pp. 255-260, 2015.

[17] S. Subramaniam, J. Rahmat, N. A. Rahman et al., "Presentation of retinoblastoma patients in Malaysia," Asian Pacific Journal of Cancer Prevention, vol. 15, no. 18, pp. 7863-7867, 2014.

[18] S. J. Park, S. J. Woo, and K. H. Park, "Incidence of retinoblastoma and survival rate of retinoblastoma patients in Korea using the Korean National Cancer Registry database (19932010)," Investigative Opthalmology \& Visual Science, vol. 55, no. 5, pp. 2816-2821, 2014.

[19] S. Okimoto and K. Nomura, "Clinical manifestations and treatment of retinoblastoma in Kobe children's hospital for 16 years," Journal of Pediatric Ophthalmology \& Strabismus, vol. 51, no. 4, pp. 222-229, 2014.

[20] F. Moreno, B. Sinaki, A. Fandiño, V. Dussel, L. Orellana, and G. Chantada, "A population-based study of retinoblastoma incidence and survival in Argentine children," Pediatric Blood \& Cancer, vol. 61, no. 9, pp. 1610-1615, 2014.

[21] M. Kruger, D. Reynders, F. Omar, J. Schoeman, O. Wedi, and J. Harvey, "Retinoblastoma outcome at a single institution in South Africa," South African Medical Journal, vol. 104, no. 12, pp. 859-863, 2014.

[22] R. A. d. R. Bastos, R. Silva, M. Gil-da-Costa et al., "Retinoblastoma: experience of a referral center in the North Region of Portugal," Clinical Ophthalmology, vol. 8, pp. 993-997, 2014.

[23] F. P. M. Lim, S. Y. Soh, J. V. Iyer, A. M. Tan, H. Swati, and B. L. Quah, "Clinical profile, management, and outcome of retinoblastoma in Singapore," Journal of Pediatric Ophthalmology \& Strabismus, vol. 50, no. 2, pp. 106-112, 2013.

[24] R. Nabie, N. Taheri, A. M. Fard, and R. F. Fouladi, "Characteristics and clinical presentations of pediatric retinoblastoma in North-western Iran," International Journal of Ophthalmology, vol. 5, no. 4, pp. 510-512, 2012.

[25] J. Zhao, S. Li, J. Shi, and N. Wang, "Clinical presentation and group classification of newly diagnosed intraocular retinoblastoma in China," British Journal of Ophthalmology, vol. 95, no. 10 , pp. 1372-1375, 2011.

[26] L. Abdu and S. Malami, "Clinicopathological pattern and management of retinoblastoma in Kano, Nigeria," Annals of African Medicine, vol. 10, no. 3, pp. 214-219, 2011.

[27] V. Essuman, C. T. Ntim-Amponsah, S. Akafo et al., "Presentation of retinoblastoma at a paediatric eye clinic in Ghana," Ghana Medical Journal, vol. 44, pp. 101-105, 2010.

[28] A. MacCarthy, J. M. Birch, G. J. Draper et al., "Retinoblastoma: treatment and survival in great britain 1963 to 2002," British Journal of Ophthalmology, vol. 93, no. 1, pp. 38-39, 2009.

[29] H. Ozdemir, N. Tacyildiz, E. Unal, G. Yavuz, H. Ugur, and K. Gunduz, "Clinical and epidemiological characteristics of retinoblastoma: correlation with prognosis in a Turkish 
pediatric oncology center," Pediatric Hematology and Oncology, vol. 24, no. 3, pp. 221-231, 2007.

[30] B. Badhu, S. P. Sah, S. K. Thakur et al., "Clinical presentation of retinoblastoma in Eastern Nepal," Clinical and Experimental Ophthalmology, vol. 33, no. 4, pp. 386-389, 2005.

[31] J. Buaboonnam, N. Narkbunnam, N. Vathana et al., "Outcomes of pediatric retinoblastoma treated with ICEV regimen: a single-center study," Pediatric Hematology and Oncology, vol. 36, no. 2, pp. 73-81, 2019.

[32] P. Wongmeerit, K. Suwanrungruang, A. Jetsrisuparb, P. Komvilaisak, and S. Wiangnon, "Trends in survival of childhood cancers in a university hospital, northeast Thailand, 19932012," Asian Pacific Journal of Cancer Prevention: APJCP, vol. 17, no. 7, pp. 3515-3519, 2016.

[33] P. Hathirat, S. Kunavisarut, A. Chuansumrit, L. Pochanukul, P. Simaroj, and P. Isarangkura, "Chemotherapy in patients with retinoblastoma," Journal of the Medical Association of Thailand, vol. 76, no. Suppl 2, pp. 85-91, 1993.

[34] L. Pochanugool, S. Kunavisarut, P. Hathirat, and S. Dangprasert, "The role of radiation therapy in retinoblastoma," Journal of the Medical Association of Thailand= Chotmaihet Thangphaet, vol. 77, no. 8, pp. 393-399, 1994.

[35] G. Chantada, F. Doz, C. B. G. Antoneli et al., "A proposal for an international retinoblastoma staging system," Pediatric Blood \& Cancer, vol. 47, no. 6, pp. 801-805, 2006.

[36] C. L. Shields, A. Mashayekhi, A. K. Au et al., "The International Classification of Retinoblastoma predicts chemoreduction success," Ophthalmology, vol. 113, no. 12, pp. 2276-2280, 2006.

[37] A. M. Leahey, "Systemic chemotherapy: a pediatric oncologyperspective," in Retinoblastoma, A. Ramasubramanian andC. L. Shields, Eds., pp. 81-85, Jaypee Brothers Medical Publishers, New Delhi, India, 2012.

[38] D. Rojanaporn, E. Chanthanaphak, R. Boonyaopas et al., "Intra-arterial chemotherapy for retinoblastoma: 8-year experience from a tertiary referral institute in Thailand," AsiaPacific journal of ophthalmology, vol. 8, pp. 211-217, 2019.

[39] F. L. Munier, M.-C. Gaillard, A. Balmer et al., "Intravitreal chemotherapy for vitreous disease in retinoblastoma revisited: from prohibition to conditional indications," British Journal of Ophthalmology, vol. 96, no. 8, pp. 1078-1083, 2012.

[40] T. Kivelä, S. Eskelin, and M. Paloheimo, "Intravitreal methotrexate for retinoblastoma," Ophthalmology, vol. 118, no. 8, p. 1689, 2011.

[41] F. L. Munier, S. Soliman, A. P. Moulin, M.-C. Gaillard, A. Balmer, and M. Beck-Popovic, "Profiling safety of intravitreal injections for retinoblastoma using an anti-reflux procedure and sterilisation of the needle track," British Journal of Ophthalmology, vol. 96, no. 8, pp. 1084-1087, 2012.

[42] J. H. Francis, X. L. Xu, Y. P. Gobin, B. P. Marr, S. E. Brodie, and D. H. Abramson, "Death by water: precautionary water submersion for intravitreal injection of retinoblastoma eyes," The Open Ophthalmology Journal, vol. 8, no. 1, pp. 7-11, 2014.

[43] S. Honavar and A. Singh, "Management of advanced retinoblastoma," Ophthalmology Clinics of North America, vol. 18, no. 1, pp. 65-73, 2005.

[44] J. H. Francis, N. Roosipu, A. M. Levin et al., "Current treatment of bilateral retinoblastoma: the impact of intraarterial and intravitreous chemotherapy," Neoplasia, vol. 20, no. 8, pp. 757-763, 2018.

[45] S. Goolam, H. Kana, N. Welsh, L. Wainwright, J. Poole, and I. Mayet, "A 20-year retrospective review of retinoblastoma at two tertiary academic hospitals in johannesburg, South
Africa," Ocular Oncology and Pathology, vol. 4, no. 3, pp. 170-175, 2018.

[46] J. L. Berry, K. Kogachi, H. A. Aziz et al., "Risk of metastasis and orbital recurrence in advanced retinoblastoma eyes treated with systemic chemoreduction versus primary enucleation," Pediatr Blood Cancer, vol. 64, no. 4, pp. 1-11, 2017.

[47] I. Al-Nawaiseh, H. M. Jammal, Y. S. Khader, I. Jaradat, and R. Barham, "Retinoblastoma in Jordan, 2003-2013: ocular survival and associated factors," Ophthalmic Epidemiology, vol. 21, no. 6, pp. 406-411, 2014.

[48] S. Luna-Fineman, M. Barnoya, M. Bonilla, L. Fu, F. Baez, and C. Rodríguez-Galindo, "Retinoblastoma in Central America: report from the central American association of pediatric hematology oncology (AHOPCA)," Pediatric Blood \& Cancer, vol. 58, no. 4, pp. 545-550, 2012.

[49] A. A. E. Ali, S. M. A. Elsheikh, A. Elhaj et al., "Clinical presentation and outcome of retinoblastoma among children treated at the national cancer institute (NCI) in gezira, Sudan: a single institution experience," Ophthalmic Genetics, vol. 32, no. 2, pp. 122-125, 2011

[50] E. Broaddus, A. Topham, and A. D. Singh, "Survival with retinoblastoma in the USA: 19752004," British Journal of Ophthalmology, vol. 93, no. 1, pp. 24-27, 2009.

[51] R. Jamalia, R. Sunder, J. Alagaratnam et al., "Retinoblastoma registry report--hospital kuala lumpur experience," Medical Journal Malaysia, vol. 65, no. Suppl A, pp. 128-130, 2010.

[52] C. L. Shields, A. Mashayekhi, H. Demirci et al., "Practical approach to management of retinoblastoma," Archives of Ophthalmology, vol. 122, no. 5, pp. 729-735, 2004.

[53] L. J. Butros, D. H. Abramson, and I. J. Dunkel, "Delayed diagnosis of retinoblastoma: analysis of degree, cause, and potential consequences," Pediatrics, vol. 109, no. 3, p. E45, 2002.

[54] J. D. Buckley, "The aetiology of cancer in the very young," The British Journal of Cancer. Supplement, vol. 18, pp. S8-S12, 1992.

[55] D. H. Abramson, C. M. Frank, M. Susman, M. P. Whalen, I. J. Dunkel, and N. W. Boyd, "Presenting signs of retinoblastoma," The Journal of Pediatrics, vol. 132, no. 3, pp. 505-508, 1998.

[56] R. F. Jubran, A. Erdreich-Epstein, A. Butturini, A. L. Murphree, and J. G. Villablanca, "Approaches to treatment for extraocular retinoblastoma," Journal of Pediatric Hematology/Oncology, vol. 26, no. 1, pp. 31-34, 2004.

[57] C. L. Shields, A. T. Meadows, J. A. Shields et al., "Chemoreduction for retinoblastoma may prevent intracranial neuroblastic malignancy (trilateral retinoblastoma)," Archives of Ophthalmology, vol. 119, no. 9, pp. 1269-1272, 2001.

[58] F. L. Munier, M. Beck-Popovic, G. L. Chantada et al., "Conservative management of retinoblastoma: challenging orthodoxy without compromising the state of metastatic grace. "Alive, with good vision and no comorbidity," Progress in Retinal and Eye Research, vol. 73, p. 100764, 2019.

[59] M. C. De Jong, W. A. Kors, P. de Graaf, J. A. Castelijns, A. C. Moll, and T. Kivelä, "The incidence of trilateral retinoblastoma: a systematic review and meta-analysis," American Journal of Ophthalmology, vol. 160, no. 6, pp. 1116-1126, 2015.

[60] E. M. Sullivan, M. W. Wilson, C. A. Billups et al., "Pathologic risk-based adjuvant chemotherapy for unilateral retinoblastoma following enucleation," Journal of Pediatric Hematology/ Oncology, vol. 36, no. 6, pp. e335-e340, 2014. 